\title{
Effects of Head-Centered Gross Motor Training on Balance, Gait and GMFM in the Children with Spastic Diplegia
}

\author{
Hyun-Joon Cho, PT, MSc ${ }^{1}$, Hye-Joo Jeon, PT, PhD ${ }^{2}$, Woo-Nam Chang, PT, PhD ${ }^{* 3}$ \\ ${ }^{1}$ Dept. of Physical Therapy, SSRO Children Center, Republic of Korea \\ ${ }^{2}$ Dept. of Physical Therapy, U1 University, Republic of Korea \\ ${ }^{* 3}$ Dept. Of Physical Therapy, College of Health \& Welfare, Yongin University, Republic of Korea
}

\begin{abstract}
Purpose This study was to investigate the effects of head-centered gross motor training on balance, trunk sway, gait and gross motor functions of children with spastic diplegia. Methods The experimental group ( $\mathrm{n}=10)$ participated in head-centered gross motor training program (30 minute per session and 2 sessions per week), while the control group $(\mathrm{n}=10)$ received regular physical therapy (30 minute per session and 2 sessions per week). Changes in static balance ability, gait ability, and gross motor functions were measured pre- and post-intervention to determine the effect of the intervention. Results The experimental group showed a significant difference in terms of trunk sway during static gait after the intervention. In the gait function test, the experimental group showed a significant difference only in single-support phase, while the control group showed a significant difference only in step width. In the gross motor function measure (GMFM), the experimental group showed significant differences in the mean of C, D, E and total whereas the control group showed significant differences in the mean of $\mathrm{D}, \mathrm{E}$ and total. In the between-groups comparison, a significant difference in only mean of $\mathrm{E}$ was found in the gross motor function measure. Conclusion Based on these findings, it was determined that head-centered gross motor training improves static balance, trunk control, and postural stability during gait, and gross motor functions in children with spastic diplegia. Improved postural stability through such head-centered gross motor training could be helpful in improving balance and postural control.
\end{abstract}

Key words Spastic diplegia, Head-centered Gross motor training, Static balance, Trunk sway, GMFM

Corresponding author Woo-Nam Chang (woonamchang@yongin.ac.kr)

Received date

Revised date

Accept date
15 Jan 2020

16 Feb 2020

18 Feb 2020

\section{Introduction}

Children with spastic diplegia have greater spasticity and dysfunction in the lower limbs than in the upper limbs, ${ }^{1)}$ which is caused by periventricular leukomalacia (PVL) arising from focal necrosis of the white matter due to surrounding cerebrovascular problems, infection/inflammation and inherent vulnerability of the brain tissue. ${ }^{2)}$ Children with spastic diplegia have primary damage in the form of reduced muscle activation, decline in selective motor control function, and abnormal muscle tone, along with secondary problems including muscle contracture and musculoskeletal deformities. ${ }^{3)}$ These primary and secondary problems have significant effects on postural control impair-

http:dx.doi.org/10.17817/2020.02.16.111533 ment, walking, and gross motor function. ${ }^{4)}$ In particular, decline in head control function in children with cerebral palsy $(\mathrm{CP})$ leads to static and dynamic postural instability, resulting in impaired postural control. ${ }^{5}$ Healthy children acquire head control and the ability to maintain their head upright at around 3-4 months after birth with the development of head stabilization. ${ }^{6}$ Head control at different head position angles is essential for postural control ${ }^{7)}$ and enhancement of this postural control leads to acquisition of gross motor skills. ${ }^{8)}$ Children with spastic diplegia, however, have impaired head control that affects three-dimensional spinal alignment and pelvic tilt, causing inaccurate body posture regulation. ${ }^{4)}$ In addition, they have difficulty maintaining proper posture and achieving balance due to altered trunk movements, ${ }^{6,9)}$ and express 
a characteristic pathological gait pattern and gross motor function problems. ${ }^{10)}$

A recent study showed that a decline in head control in children with spastic diplegia affects trunk sway and reduces dynamic stability of the head and trunk compared with the gait of normal children." These results suggest that head/trunk stability is integral to spinal stability and balance maintenance and greatly affect gross motor function. ${ }^{11,12)}$ Children with spastic diplegia with mild impairment of gross motor function tend to fix the head and trunk as a single unit and thus show increased lateral bending, while moderately impaired children show high instability due to a greater increase in trunk sway in all three dimensions. ${ }^{9}$ 13) Therefore, providing the opportunity for normal development of movement, along with head/trunk stability, is highly critical to resolving postural instability. ${ }^{11)}$

In a previous study of children with spastic diplegia, supporting the head for stability during walking induced less trunk sway than supporting the thoracic, which suggests that increasing head stability with head-centric sensory signals enhances trunk control and optimizes gait and is thus highly important for postural control. ${ }^{14)}$ Such improvement in head control effectively increases trunk stability and improves static and dynamic balance, as well as gross motor function. ${ }^{15)}$ However, previous studies investigated the effects of proximal exercise intervention for the respective body part but there have been no reports on the effects of head-centered gross motor training on balance and gait. The present study thus aimed to investigate the effects of head-centered gross motor training on balance, gait, and gross motor function in children with spastic diplegia. The study was conducted with the approval of the Institutional Review Board at YongIn University (approval number 2-1040966-AB-N-01-201903-HSR-135-2).

\section{Materials and Methods}

\section{Subjects}

Twenty patients with spastic diplegia aged 3-15 years or below who visited clinic B in Gyeonggi Province as an inpatient from January to March 2019, capable of independent walking corresponding to Gross Motor Function Classification System (GMFCS) level 1-3, and consented to participate were included in this study. For each GMFCS level, we randomly assigned participants using Microsoft Excel. Participants were children without any cognitive problem, capable of following instructions, and who had not undergone botulinum toxin injection or received surgical treatment within the last 6 months.

\section{Procedure}

In this study, the experimental group received the head-centered gross motor training program, while the control group received standard physical therapy twice a week, 30 minutes per session, for 8 weeks.

\section{1) Head-centered gross motor training program}

This experimental program was conducted by a physical therapist who had expert knowledge in neurodevelopmental treatment. We developed a head-centered gross motor training program, consisting of five domains for a total of six program types, by applying gross motor functions such as supine to sitting, side-lying to sitting, prone to kneeling, sit to standing, and walking. The programs were administered for 5 minutes each, for a total of 30 minutes (Figure 1). ${ }^{16,17)}$

\section{2) Standard physical therapy}

Standard physical therapy was conducted by a physical therapist who had expert knowledge in neurodevelopmental treatment. The program for standard physical therapy included exercises for joint mobilization and stretching, muscle strengthening, weight bearing, postural control, and walking.

\section{Measurements}

\section{1) Static balance ability}

To assess the static balance of children with spastic diplegia, we used Biorescue (RM Ingenieri, France). Participants were asked to stand barefoot on the platform and maintain a standing posture for 5 seconds without moving, while looking at a visual marking 


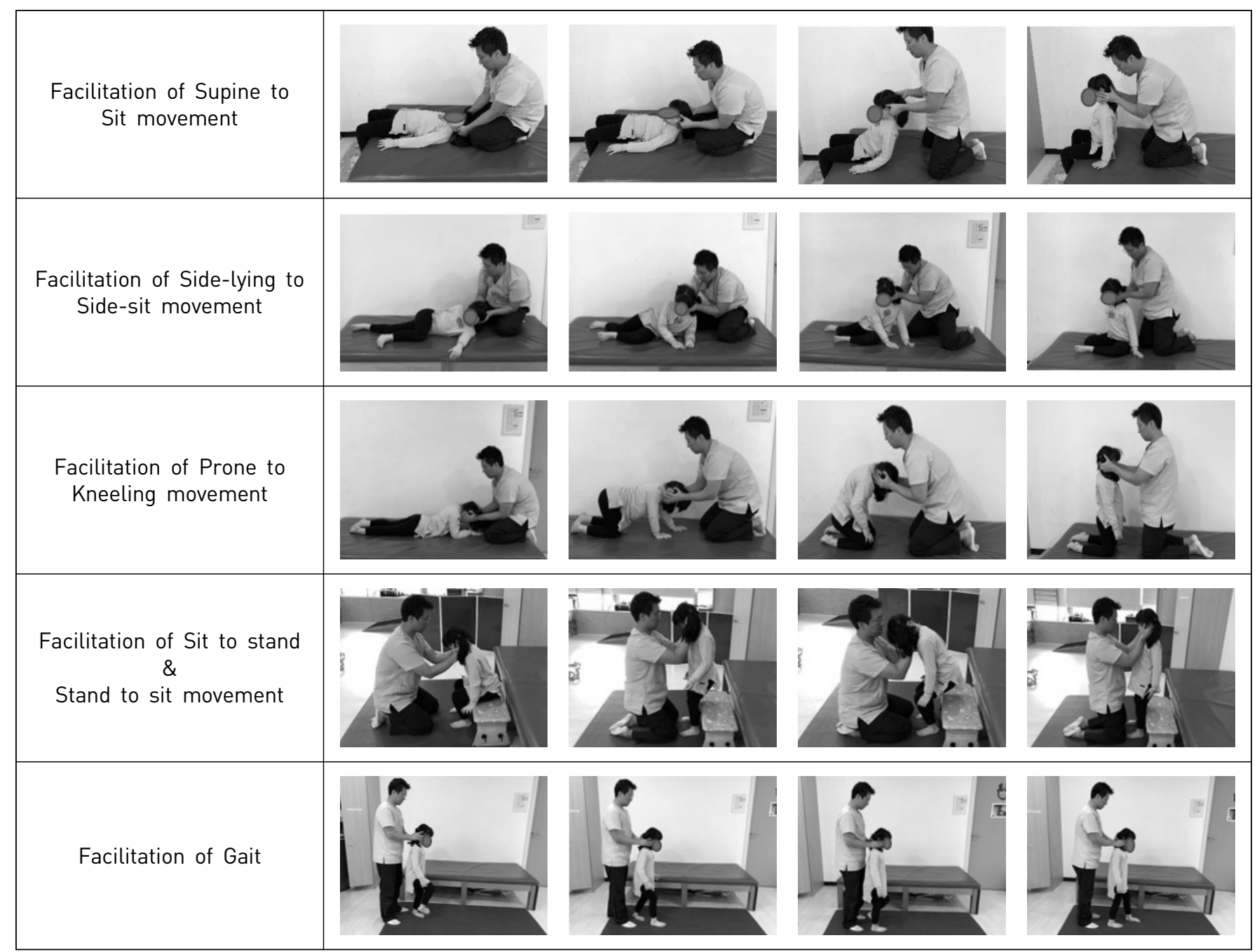

Figure 1. Intervention of Head-centered gross motor training program

placed in front of them at eye-level. We obtained a total of three measurements in the standing position and measured the center of mass (COM) and center of pressure (COP) during left and right weight-bearing to compare the ratio of left/right weight-bearing area and pressure.

\section{2) Comparison of changes in trunk sway displacement}

To measure the magnitude of trunk sway from the gait parameters, we used Balance Gear (ALDA, Taiwan), which measures the forward/backward (pitch), inward/outward (roll), and upward/downward (yaw) displacements of trunk movement. ${ }^{18)}$ Participants stood barefoot on the floor throughout measurement and simultaneously underwent functional gait assessment. We placed the middle portion of the device on the participant's xiphoid process using an elastic band and ensured that the sensor was aligned with the midline before the participant started walking. Each participant walked a total of $4 \mathrm{~m}$ three times, while the trunk angular sway was measured.

We extracted the roll data (angular displacement from the trunk midline to the left $(-)$ or right $(+)$ side in the frontal plane). The extracted data were then converted to radians to compute the trunk sway distance to the left and right using the sine trigonometric function. For each of the three calculations of sway distance, we included data up to the tenth stride, excluding first stride data. 


\section{3) Gait analysis}

To measure the spatiotemporal gait parameters, we used the two-dimensional Optogait system (Microgate, Italy) as the gait analyzer. Two-dimensional analysis is enabled by positioning all transmission/reception bars within $1 \mathrm{~m}$ horizontally and $4 \mathrm{~m}$ vertically, allowing for correction of errors due to overlapping motion during measurement and accurate analysis of the measured gait parameters. Participants waited standing barefoot on the floor within the transmission/reception area and started walking following the researcher's "Go" signal towards the opposite end at their desired speed. The measurement was performed a total of three times and the collected gait parameter data were processed using software (Microgate, Italy).

\section{4) Korean Gross Motor Function Measure 88 (K-GMFM88)} To assess the gross motor function, we used the K-GMFM88. Evaluation criteria were divided into a total of five domains: A lying and rolling; B sitting; C crawling and kneeling; D standing; and E walking, running, and jumping. Of the five domains, we used the scores for domains $\mathrm{C}, \mathrm{D}, \mathrm{E}$, and the total score to compare results.

\section{Data analysis}

In this study, SPSS 22.0 program for Windows was used. Difference between pre- and post-test were analyzed by The general characteristics of the subjects were calculated by using descriptive statistics to mean and standard deviation, and the Shapiro-Wilk test was performed to verify the normality of the measured data. Difference between pre- and post-test were ana- lyzed by Wilcoxon rank sum test and Mann-Whitney $\mathrm{U}$ test was performed to compare differences between the groups. Statistically significant levels were $=$ to 0.05 .

\section{Results}

\section{Static balance ability}

We analyzed the ratio of left/right weight-bearing areas in standing posture and found that the area significantly decreased by $7.94 \%$, from $13.23 \%$ to $5.29 \%$, in the experimental group following intervention $(p<.05)$, whereas in the control group, the area increased by $0.04 \%$, from $10.96 \%$ to $11.00 \%$, which was not statistically significant $(p>.05)$. We analyzed the ratio of left/right weight-bearing pressure and found that the pressure significantly decreased by $14.71 \%$, from $19.99 \%$ to $5.28 \%$, in the experimental group following intervention $(p<.05)$, whereas in the control group, the area had decreased by $2.49 \%$, from $20.43 \%$ to $17.94 \%(p>.05)$. No significant between-group differences were found in these two analyses $(p>.05)$ (Table 1).

\section{Comparison of changes in trunk sway distance}

We analyzed the changes in trunk sway during the 4-m walk and found that sway distance significantly decreased by $1.55 \mathrm{~cm}$, from $9.67 \mathrm{~cm}$ to $8.12 \mathrm{~cm}$, in the experimental group following intervention $(p<.05)$, whereas in the control group, the distance changed from $10.57 \mathrm{~cm}$ to $10.87 \mathrm{~cm}$, which was not statistically significant $(p>.05)$ Between-group comparison revealed

Table 1. Comparison of static symmetry, trunk sway within and between groups.

\begin{tabular}{|c|c|c|c|c|c|c|c|c|c|c|c|}
\hline \multirow[b]{2}{*}{ Variable } & \multicolumn{4}{|c|}{ Experimental group $(n=10)$} & \multicolumn{5}{|c|}{ Control group $(n=10)$} & \multirow[b]{2}{*}{$z$} & \multirow[b]{2}{*}{$p$} \\
\hline & pre & & post & $\begin{array}{l}\text { Change } \\
\text { (post-pre) }\end{array}$ & & pre & & post & $\begin{array}{l}\text { Change } \\
\text { [post-pre) }\end{array}$ & & \\
\hline $\begin{array}{c}\text { Foot print } \\
\text { area }\end{array}$ & $13.23 \pm$ & 7.95 & $5.29 \pm 3.08$ & $8.53 \pm 6.65^{*}$ & 10.96 & \pm & 5.96 & $11.00 \pm 5.80$ & $6.23 \pm 5.74$ & -0.983 & 0.326 \\
\hline $\begin{array}{c}\text { Foot print } \\
\text { pressure }\end{array}$ & $19.99 \pm$ & 10.64 & $5.28 \pm 4.67$ & $15.00 \pm 10.91^{*}$ & 20.43 & \pm & 11.26 & $17.94 \pm 9.77$ & $8.33 \pm 5.60$ & -1.361 & 0.174 \\
\hline Trunk sway & $9.67 \pm$ & 3.53 & $8.12 \pm 3.86$ & $1.85 \pm$ & 10.57 & \pm & 4.58 & $10.87 \pm 4.45$ & $1.11 \pm 0.62$ & -1.739 & 0.082 \\
\hline
\end{tabular}

$\mathrm{M} \pm \mathrm{SD}$ : mean \pm standard deviation, $\mathrm{p}<0.05 *$ 
Table 2. Comparison of gait analysis variables within and between groups.

\begin{tabular}{|c|c|c|c|c|c|c|c|c|c|c|c|c|c|c|}
\hline \multirow[b]{2}{*}{ Variable } & \multicolumn{6}{|c|}{ Experimental group $(n=10)$} & \multicolumn{6}{|c|}{ Control group $(n=10)$} & \multirow[b]{2}{*}{$z$} & \multirow[b]{2}{*}{$p$} \\
\hline & pre & & pos & & $\begin{array}{r}\text { Chan } \\
\text { lpost- }\end{array}$ & $\begin{array}{l}\text { prel } \\
\text { pe }\end{array}$ & pre & & post & & $\begin{array}{r}\text { Chang } \\
\text { lpost-p }\end{array}$ & $\begin{array}{l}\text { ge } \\
\text { orel }\end{array}$ & & \\
\hline $\begin{array}{l}\text { Speed, } \\
\mathrm{cm} / \mathrm{min}\end{array}$ & $0.69 \pm$ & 0.23 & $0.60 \pm$ & 0.18 & $0.17 \pm$ & 0.10 & $0.61 \pm$ & 0.29 & $0.59 \pm$ & 0.24 & $0.19 \pm$ & 0.17 & -0.41 & 0.67 \\
\hline $\begin{array}{l}\text { Cadence, } \\
\text { steps/min }\end{array}$ & $118.23 \pm$ & 26.74 & $110.60 \pm$ & 18.59 & $16.17 \pm$ & 9.90 & $102.44 \pm$ & 40.42 & $106.47 \pm$ & 43.40 & $20.30 \pm$ & 21.15 & -0.60 & 0.54 \\
\hline $\begin{array}{l}\text { Step length, } \\
\mathrm{cm}\end{array}$ & $34.90 \pm$ & 6.85 & $32.27 \pm$ & 5.88 & $3.97 \pm$ & 2.51 & $37.12 \pm$ & 8.54 & $34.28 \pm$ & 8.54 & $7.10 \pm$ & 5.38 & -1.09 & 0.27 \\
\hline $\begin{array}{c}\text { Stride } \\
\text { length, cm }\end{array}$ & $69.76 \pm$ & 13.33 & $64.93 \pm$ & 11.08 & $7.60 \pm$ & 5.57 & $74.02 \pm$ & 17.71 & $68.79 \pm$ & 16.69 & $14.08 \pm$ & 10.69 & -1.28 & 0.19 \\
\hline $\begin{array}{c}\text { Step width, } \\
\mathrm{cm}\end{array}$ & $14.66 \pm$ & 3.45 & $15.29 \pm$ & 3.47 & $14.66 \pm$ & 3.45 & $16.57 \pm$ & 7.35 & $14.41 \pm$ & 6.37 & $16.57 \pm$ & $7.35^{*}$ & -0.60 & 0.54 \\
\hline $\begin{array}{c}\text { Single } \\
\text { support, \% }\end{array}$ & $35.29 \pm$ & 8.14 & $31.35 \pm$ & 3.60 & $5.19 \pm$ & $8.41^{*}$ & $41.38 \pm$ & 22.67 & $37.31 \pm$ & 10.51 & $8.55 \pm$ & 11.70 & -1.66 & 0.09 \\
\hline $\begin{array}{c}\text { Double } \\
\text { support, \% }\end{array}$ & $33.29 \pm$ & 11.64 & $40.03 \pm$ & 7.65 & $8.29 \pm$ & 11.94 & $27.38 \pm$ & 27.36 & $31.03 \pm$ & 17.90 & $9.11 \pm$ & 9.97 & -0.90 & 0.36 \\
\hline $\begin{array}{c}\text { Stance } \\
\text { phase, \% }\end{array}$ & $68.27 \pm$ & 3.94 & $70.73 \pm$ & 3.64 & $3.30 \pm$ & 3.34 & $68.18 \pm$ & 5.76 & $66.94 \pm$ & 7.78 & $3.39 \pm$ & 2.85 & -0.15 & 0.88 \\
\hline $\begin{array}{c}\text { Swing } \\
\text { phase, \% }\end{array}$ & $31.54 \pm$ & 3.79 & $29.04 \pm$ & 3.58 & $3.47 \pm$ & 3.03 & $32.71 \pm$ & 5.76 & $33.07 \pm$ & 7.62 & $2.87 \pm$ & 2.33 & -0.03 & 0.97 \\
\hline
\end{tabular}

$\mathrm{M} \pm \mathrm{SD}$ : mean \pm standard deviation, $\mathrm{p}<0.05 *$

no significant difference $(p>.05)$ (Table 1$)$.

\section{Gait analysis}

We analyzed the spatiotemporal parameters identified through gait analysis in the experimental and control groups and obtained the following results. In the experimental group, the single support time significantly decreased by $3.94 \%$, from $35.29 \%$ to $31.35 \%$, following intervention $(p<.05)$, while in the control group it decreased by $4.07 \%$, from $41.38 \%$ to $37.31 \%$ ( $p>.05$ ). In the control group, the step width significantly decreased by $2.16 \mathrm{~cm}$, from $16.57 \mathrm{~cm}$ to $14.41 \mathrm{~cm}$ $(p<.05)$ (Table 2).

\section{Korean Gross Motor Function Measure 88 (K-GMFM88)}

Analysis of the K-GMFM88 results revealed that in the experimental group, C crawling \& kneeling increased by $2.16 \%$, from $94.97 \%$ to $97.13 \%$; D standing in- creased by $5.87 \%$, from $78.96 \%$ to $84.83 \%$; and $\mathrm{E}$ walking, running and jumping increased by $9.85 \%$, from $63.59 \%$ to $73.44 \%$, which were all significant changes $(p<.05)$. In addition, the mean total score increased by $5.96 \%$, from $79.17 \%$ to $85.13 \%$, which was also a significant change $(p<.05)$.

The before-after comparison in the control group revealed that $\mathrm{D}$ standing significantly increased by $2.32 \%$, from $70.45 \%$ to $72.77 \%$ and $\mathrm{E}$ walking, running and jumping changed by $2.48 \%$, from $53.30 \%$ to $55.78 \%(p<.05)$. On the other hand, C crawling \& kneeling increased by $0.95 \%$, from $91.62 \%$ to $92.57 \%$, which was not significant $(p>.05)$. Moreover, the mean total score showed a significant change from $71.79 \%$ to $73.70 \%(p<.05)$.

Between-group comparison of the rate of change in gross motor function revealed no significant difference, with C crawling \& kneeling at $2.16 \%$ and $0.95 \%$, and D standing at $5.84 \%$ and $2.32 \%(p>.05)$. E walk- 
Table 3. Comparison of gross motor function within and between groups.

\begin{tabular}{|c|c|c|c|c|c|c|c|c|c|c|c|c|c|c|}
\hline \multirow[b]{2}{*}{ Variable } & \multicolumn{6}{|c|}{ Experimental group $(n=10)$} & \multicolumn{6}{|c|}{ Control group $(n=10)$} & \multirow[b]{2}{*}{$z$} & \multirow[b]{2}{*}{$p$} \\
\hline & $\mathrm{pr}$ & & pos & & & $\begin{array}{l}\text { tange } \\
\text { st-prel }\end{array}$ & pr & & & ost & & $\begin{array}{l}\text { Change } \\
\text { (post-pre) }\end{array}$ & & \\
\hline $\begin{array}{l}\text { C. Crawling } \\
\text { and } \\
\text { kneeling } \\
\text { (range) }\end{array}$ & $94.97 \pm$ & 6.31 & $97.13 \pm$ & 5.25 & 2.16 & $\pm 2.38^{*}$ & $91.62 \pm$ & 4.80 & 92.57 & \pm & 4.42 & $0.85 \pm 1.65$ & -1.33 & 0.18 \\
\hline $\begin{array}{l}\text { D. Standing } \\
\text { (range) }\end{array}$ & $78.96 \pm$ & 9.73 & $84.83 \pm$ & 6.90 & 5.87 & $\pm 4.68^{*}$ & $70.45 \pm$ & 10.20 & 72.77 & \pm & 9.82 & $2.32 \pm 2.83^{*}$ & -1.70 & 0.09 \\
\hline $\begin{array}{l}\text { E. Walking, } \\
\text { running and } \\
\text { jumping } \\
\text { (range) }\end{array}$ & $63.59 \pm$ & 16.97 & $73.44 \pm$ & 16.44 & 9.85 & $\pm 6.86^{* *}$ & $53.30 \pm$ & 15.17 & 55.78 & \pm & 15.89 & $2.48 \pm 1.82^{*}$ & -2.77 & $0.01^{* *}$ \\
\hline $\begin{array}{c}\text { Average } \\
\text { score } \\
\text { (range) }\end{array}$ & $79.17 \pm$ & 9.82 & $85.13 \pm$ & 8.01 & 5.96 & $\pm 2.97^{* *}$ & $71.79 \pm$ & 8.74 & 73.70 & \pm & 9.04 & $1.91 \pm 1.52^{*}$ & -3.03 & $0.01^{* *}$ \\
\hline
\end{tabular}

$\mathrm{M} \pm \mathrm{SD}:$ mean \pm standard deviation, $\mathrm{p}<0.05 *, \mathrm{p}<0.01 * *$

ing, running and jumping, however, showed a significant difference between the two groups, $9.85 \%$ and $2.48 \%(p<.05)$. The mean total scores were $5.96 \%$ and $1.91 \%$, which was also a significant difference $(p<.05)$ (Table 3).

\section{Discussion}

This study was conducted to investigate the effects of the head-centered gross motor training program on balance, gait, and gross motor function in spastic diplegia. Until about the age of 6 years, coordinated movements using head control are highly crucial for maintaining balance and at approximately the age of 7-8 years, more information comes from the balance control centers than from head position, which suggests that the development of head control is critically implicated in the development of balance. ${ }^{16,}{ }^{19)}$ In addition, standing posture, an example of static balance, requires anti-gravity posture orientation for maintaining body alignment against gravity and postural stability in base of support (BOS). ${ }^{20)}$ Trunk muscles must be activated via anticipatory postural control to provide proximal stability and minimize body sway, thus enabling smooth distal movements. ${ }^{21}$ The present study thus aimed to evaluate the left/right symmetry during static balance by exploring differences in the ratio of left/right weight-bearing area and pressure in the base of support in the standing posture.

The results of the static balance ability measurement showed that in the experimental group, the symmetry increased as the difference in the ratio of left/right weight-bearing area and pressure decreased following the intervention. Such results of static balance assessment are consistent with previous findings that improvement in head control leads to enhanced head-trunk connectivity, balance, and proprioception. ${ }^{22,23)}$

Head control is also known to play an integral role in gait development, ${ }^{24)}$ but there is almost no literature on differences between the head and trunk during walking in spastic diplegia and research is focused mainly on the effects of lower limb damage, rather than the movements of the head and trunk. ${ }^{25}$ Nevertheless, a previous study by Wallard ${ }^{13)}$ analyzed the range of head and trunk sway during walking in $\mathrm{CP}$ children and found a significant change in the rotational angle of the head roll in the frontal plane. Therefore, CP children use the "en bloc" strategy when it is difficult or impossible to make separate rotational movements of the head and trunk, in which the head and trunk move together as a single unit, 
thereby limiting the degrees of freedom, and display a gait pattern with increased trunk sway.

Accordingly, the present study also found a significant decrease in the trunk sway distance during the 4-m walk; following intervention, trunk sway decreased by $1.55 \mathrm{~cm}$, from $9.67 \pm 3.53$ to $8.12 \pm 3.86 \mathrm{~cm}$, only in the experimental group $(p<.05)$. Another previous study by Schulleri ${ }^{14)}$ demonstrated a decrease in sway with interpersonal touch (IPT) at the apex and occiput area and not with thoracic support in CP children, but this change was not significant. These findings support the results of the present study based on head stabilization.

In the functional gait assessment, we could not confirm that the head-centered gross motor training program significantly affected gait, contrary to our experimental hypothesis. The gait assessment results showed that only single support significantly decreased by $3.94 \%$, from $35.29 \pm 8.14 \%$ to $31.35 \pm 3.60 \%$ in the experimental group $(p<.05)$. This suggests the presence of several other underlying reasons for CP-related difficulties with achieving or controlling proper posture and unstable gait pattern. ${ }^{26)}$ Factors influencing gait in $\mathrm{CP}$ include ankle stability ${ }^{27)}$ and hip movement ${ }^{9}{ }^{28,29)}$; thus, it is difficult to change gait using head control alone. However, in the present study, we confirmed a significant change in single support in the experimental group, as well as a $6.74 \%$ increase in double support from $33.29 \pm 11.64 \%$ to $40.03 \pm 7.65 \%$, a non-significant $2.46 \%$ increase in stance phase, from $68.27 \pm 3.94$ to $70.73 \pm 3.64$, and an increase in mean support stability, through which we can conclude that dynamic instability affects gait.

Finally, the K-GMFM results revealed a significant within-group change following intervention in the experimental group $(p<.05)$. In the control group, however, there was a significant change in standing; walking, running, and jumping; and the total score $(p<.05)$, but there was no significant change in crawling and kneeling $(p<.05)$. These results are consistent with previous findings that improvements in head stabilization affects the increase of range of motion and motor function. ${ }^{15,22)}$ Such findings support the results of the present study.
In conclusion, we believe that the head-centered gross motor training program positively affected static balance, trunk sway, gait stability, and gross motor function in diplegic CP children. We have provided the therapeutic evidence and rationale for using the head-centered gross motor training program to enhance postural control. Furthermore, the proposed program can be delivered not only by physical therapists but also through parental education so that the child can independently perform the functional movements and apply them to daily activities. We expect it to be used as the basis for the development of home training programs, therapy, and research in the future. Nevertheless, this study has limitations in its small sample size, short intervention period, and wide range of subject ages. A follow-up study to reinforce the evidence of this intervention program is required.

\section{References}

1. Aarnoudse-Moens CSH, Weisglas-Kuperus N, van Goudoever JB, et al. Meta-analysis of neurobehavioral outcomes in very preterm and/or very low birth weight children. Pediatrics. 2009;124(2):717-28.

2. Volpe JJ, Kinney HC, Jensen FE, et al. The developing oligodendrocyte: Key cellular target in brain injury in the premature infant. Int J Dev Neurosci. 2011;29(4): 423-40.

3. Koman LA, Smith BP, Shilt JS. Cerebral palsy. The Lancet. 2004;363(9421):1619-31.

4. Domagalska-Szopa M, Szopa A. Postural orientation and standing postural alignment in ambulant children with bilateral cerebral palsy. Clinical Biomechanics. 2017;49:22-7.

5. Rosenbaum P, Paneth N, Leviton A, et al. A report: The definition and classification of cerebral palsy april 2006. Developmental medicine and child neurology Supplement. 2007;109:8-14.

6. Saavedra S, Woollacott M, Van Donkelaar PJEbr. Head stability during quiet sitting in children with cerebral palsy: Effect of vision and trunk support. 2010;201(1): 13-23.

7. Pozzo T, Levik Y, Berthoz A. Head and trunk movements in the frontal plane during complex dynamic equilibrium tasks in humans. Experimental Brain Research. 
1995;106(2):327-38.

8. Assaiante C. Development of locomotor balance control in healthy children. Neuroscience \& Biobehavioral Reviews. 1998;22(4):527-32.

9. Heyrman L, Feys H, Molenaers G, et al. Threedimensional head and trunk movement characteristics during gait in children with spastic diplegia. Gait \& Posture. 2013;38(4):770-6.

10. Van de Walle P, Hallemans A, Truijen S, et al. Increased mechanical cost of walking in children with diplegia: The role of the passenger unit cannot be neglected. Research in developmental disabilities. 2012;33(6): 1996-2003.

11. Bobath B, Bobath K. Motor development in the different types of cerebral palsy. W. Heinemann Medical Books, 1988.

12. Tecklin JS. Pediatric physical therapy. Lippincott Williams \& Wilkins, 2008.

13. Wallard L, Bril B, Dietrich G, et al. The role of head stabilization in locomotion in children with cerebral palsy. Annals of Physical and Rehabilitation Medicine. 2012;55(9):590-600.

14. Schulleri KH, Burfeind F, Höß-Zenker B, et al. Deliberately light interpersonal contact affects the control of head stability during walking in children and adolescents with cerebral palsy. Archives of Physical Medicine and Rehabilitation. 2017;98(9):1828-35.

15. Shin JW, Song GB, Ko JY. The effects of neck and trunk stabilization exercises on cerebral palsy children's static and dynamic trunk balance: Case series. Journal of physical therapy science. 2017;29(4):771-4.

16. Elnora G, Ann P, Josephine C. Children adapt. Charles B Slack, Inc, Thorofare, NJ. 1981.

17. Bly L. Motor skills acquisition in the first year: An illustrated guide to normal development. Elsevier Science \& Technology Books, 1998.

18. Soon K, Lee M, Tsai W, et al. A new trunk sway assessment protocol using biofeedback inertial-based sensing modality for stroke patients. In: Proceedings 2011 International Conference on System Science and Engineering. 2011. 675-8.
19. Assaiante C, Mallau S, Viel S, et al. Development of postural control in healthy children: A functional approach. Neural plasticity. 2005;12(2-3):109-18.

20. Shumway-Cook A, Woollacott MH. Motor control : Translating research into clinical practice. Lippincott Williams \& Wilkins, 2012.

21. Aruin AS, Forrest WR, Latash ML. Anticipatory postural adjustments in conditions of postural instability. Electroencephalography and Clinical Neurophysiology/ Electromyography and Motor Control. 1998;109(4): 350-9.

22. Han SJ, Lee BH, Chung EJ. The effects of cranio-cervical flexion based trunk stabilization exercise on muscle tone and sitting balance in children with spastic cerebral palsy. Journal of Special Education \& Rehabilitation Science. 2018;57(3):413-32.

23. Assaiante C, Amblard B. An ontogenetic model for the sensorimotor organization of balance control in humans. Human Movement Science. 1995;14(1):13-43.

24. Forssberg H. Neural control of human motor development. Current Opinion in Neurobiology. 1999;9(6):676-82.

25. Heyrman L, Feys H, Molenaers G, et al. Threedimensional head and trunk movement characteristics during gait in children with spastic diplegia. Gait \& Posture. 2013;38(4):770-6.

26. Bruijn SM, Millard M, van Gestel L, et al. Gait stability in children with cerebral palsy. Research in Developmental Disabilities. 2013;34(5):1689-99.

27. Jang HE. The effect of hinged ankle foot orthoses on dynamic postural control during gait initiation in children with spastic cerebral palsy. Korea University, master's thesis, 2012.

28. Kiernan D, O'Sullivan R, Malone A, et al. Pathological movements of the pelvis and trunk during gait in children with cerebral palsy: A cross-sectional study with 3-dimensional kinematics and lower lumbar spinal loading. Physical Therapy. 2018;98(2):86-94.

29. Stief F, Böhm H, Ebert C, et al. Effect of compensatory trunk movements on knee and hip joint loading during gait in children with different orthopedic pathologies. Gait \& Posture. 2014;39(3):859-64. 